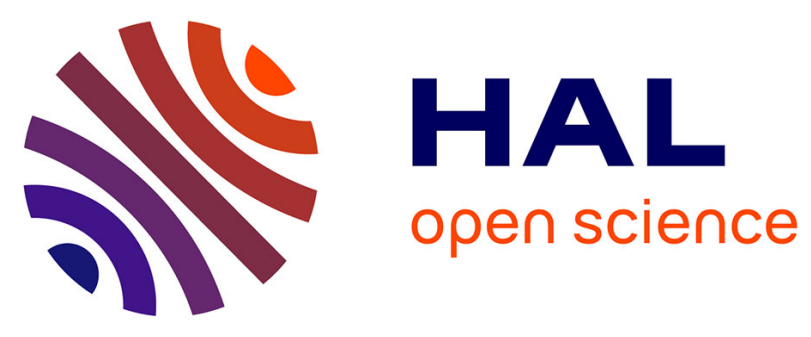

\title{
Does amnesia specifically predict Alzheimer's pathology? A neuropathological study
}

Maxime Bertoux, Pascaline Cassagnaud, Thibaud Lebouvier, Florence Lebert, Marie Sarazin, Isabelle Le Ber, Bruno Dubois, Brain Bank, Sophie Auriacombe, Didier Hannequin, et al.

\section{To cite this version:}

Maxime Bertoux, Pascaline Cassagnaud, Thibaud Lebouvier, Florence Lebert, Marie Sarazin, et al.. Does amnesia specifically predict Alzheimer's pathology? A neuropathological study. Neurobiology of Aging, In press. hal-02898941

\section{HAL Id: hal-02898941 https://hal.science/hal-02898941}

Submitted on 14 Jul 2020

HAL is a multi-disciplinary open access archive for the deposit and dissemination of scientific research documents, whether they are published or not. The documents may come from teaching and research institutions in France or abroad, or from public or private research centers.
L'archive ouverte pluridisciplinaire HAL, est destinée au dépôt et à la diffusion de documents scientifiques de niveau recherche, publiés ou non, émanant des établissements d'enseignement et de recherche français ou étrangers, des laboratoires publics ou privés. 


\section{Does amnesia specifically predict Alzheimer's pathology? A neuropathological study.}

Maxime Bertoux**a $^{1 \mathrm{a}}$, Pascaline Cassagnaud ${ }^{\mathrm{b}}$, Thibaud Lebouvier* ${ }^{\mathrm{c}}$, Florence Lebert ${ }^{\mathrm{a}}$, Marie Sarazin ${ }^{\mathrm{de}}$, Isabelle Le Ber $^{\mathrm{fg}}$, Bruno Dubois ${ }^{\mathrm{fg}}$, NeuroCEB Brain Bank, Sophie Auriacombe ${ }^{\mathrm{h}}$, Didier Hannequin ${ }^{\mathrm{i}}$, David Wallon ${ }^{\mathrm{i}}$, Mathieu Ceccaldi ${ }^{\mathrm{j}}$, Claude-Alain Maurage ${ }^{\mathrm{k}}$, Vincent Deramecourt ${ }^{\mathrm{c}}$, Florence Pasquier ${ }^{\mathrm{a}}$

a Univ Lille, Lille Neuroscience \& Cognition (Inserm UMRS1172) Degenerative and vascular cognitive disorders, CHU Lille, Laboratory of Excellence Distalz (Development of Innovative Strategies for a Transdisciplinary approach to ALZheimer's disease). F-59000, Lille, France.F-59000, Lille, France. b Univ Lille, CHU Lille, Laboratory of Excellence Distalz (Development of Innovative Strategies for a Transdisciplinary approach to ALZheimer's disease). F-59000, Lille, France.F-59000, Lille, France. c Univ Lille, Lille Neuroscience \& Cognition (Inserm UMRS1172) Alzheimer \& Taupathies, CHU Lille, Laboratory of Excellence Distalz (Development of Innovative Strategies for a Transdisciplinary approach to ALZheimer's disease). F-59000, Lille, France.

d Unit of Neurology of Memory and Language, GHU-Paris Psychiatrie et Neurosciences, Université Paris Descartes, Sorbonne Paris Cité. F-75014, Paris, France

e UMR 1023 IMIV, Service Hospitalier Frédéric Joliot, CEA, Inserm, Université Paris Sud, CNRS, Université Paris-Saclay. F-91400 Orsay, France

f Brain \& Spine Institute, UMR 975. F-75013, Paris, France.

g CHU Pitié-Salpêtrière, IM2A, Neurology Department. F-75013, Paris, France.

h CHU Bordeaux, Neurology Department. F-33000, Bordeaux, France.

i Univ Rouen, CHU Charles Nicolle, Neurology Department. F-76000, Rouen, France.

j CHU La Timone, Neurology and Neuropsychology Department. F-13000, Marseille, France.

k Univ Lille, Lille Neuroscience \& Cognition (Inserm UMRS1172), Development and Plasticity of the

Neuroendocrine Brain, Lille, France.

1 Univ Lille, CHU Lille, Department of Neuropathology, Lille, France.

1 Corresponding author.

Full contact information: CMRR, Neurologie, Hôpital R. Salengro, Rue Emile Laine, Lille 59000 France.

Phone: +33320445962; Email: maxime.bertoux@inserm.fr

* These authors contributed equally to this study.

Wordcount: Text: 3485 Abstract: 150; Title: 82 (characters count)

Number of references: 50 Tables: 2 Figures: 2

The authors report no disclosure relevant to the manuscript.

Maxime Bertoux conducted the statistical analysis.

Pascaline Cassagnaud, pascaline.cassagnaud@chru-lille.fr

Thibaud Lebouvier, thibaud.lebouvier@gmail.com

Florence Lebert, florence.lebert@ chru-lille.fr

Marie Sarazin, m.sarazin@ch-sainte-anne.fr

Isabelle Le Ber, isabelle.leber@courriel.upmc.fr

Bruno Dubois, bruno.dubois@psl.aphp.fr

Sophie Auriacombe, sophie.auriacombe@chu-bordeaux.fr

Didier Hannequin, didier.hannequin@chu-rouen.fr

David Wallon, david.wallon@chu-rouen.fr

Mathieu Ceccaldi, mathieu-pierre.ceccaldi@ap-hm.fr

Claude-Alain Maurage, claude-alain.maurage@chru-lille.fr

Vincent Deramecourt, vincent.deramecourt@chru-lille.fr

Florence Pasquier, florence.pasquier@chru-lille.fr

\section{Disclosure}

No author has a financial or commercial involvement that may present a conflict of interest pertaining to the current paper. The study is not industry-sponsored. 


\section{Highlights}

- Amnesia is traditionally considered as the key clinical symptom of AD;

- A third of patients with AD pathology were non-amnesic at presentation;

- Almost half of patients without AD pathology were amnesic at presentation;

- Memory performance has a poor accuracy to predict AD pathology; 


\begin{abstract}
Amnesia is a key component of Alzheimer's disease (AD) and the most important feature of its clinical diagnosis but its specificity has recently been challenged. This study investigated the ability of amnesia to predict AD in a clinicopathological dementia series. Ninety-one patients to which free and cued verbal memory assessment was administered during early cognitive decline, were followed until autopsy. Patients' histological diagnoses were classified as pure-AD, mixed-AD and non-AD pathologies. Data-driven automated classification procedures explored the correspondence between memory performance and pathological diagnoses. Classifications revealed three clusters of performance reflecting different levels of amnesia. Little correspondence between these clusters and the presence of $\mathrm{AD}$ pathology was retrieved. A third of patients with pure/mixed $\mathrm{AD}$ pathology were nonamnesic at presentation and $\approx 45 \%$ of patients without AD pathology were amnesic. Datadriven prediction of AD pathology based on memory also had a poor accuracy. Free and cued memory assessments are fair tools to diagnose an amnesic syndrome but lack of accuracy to predict AD pathology.
\end{abstract}

Keywords. Alzheimer's disease, AD pathology, FCSRT, Free \& Cued, Memory, Amnesia 


\section{Introduction}

Amnesia is a central feature of Alzheimer's disease (AD) and belongs to the earliest and most prominent symptoms of typical AD. In the last decades, characterisation of the memory impairment due to $\mathrm{AD}$ came as a major diagnosis advance, when pathophysiological biomarkers were still in their infancy (Grober \& Buschke, 1987; Pasquier et al., 2001; Dubois et al., 2004). Free and cued memory tests, in particular, allowed the delineation of different components of memory (Grober \& Buschke, 1987). Amnesia, when characterized by storage difficulties, was shown to be the best clinical marker of typical AD (Pasquier et al., 2001; Sarazin et al., 2007; Teichmann et al., 2017). This assumed specificity of amnesia to AD strongly impacted the field and helped to identify typical AD in health care settings. While nowadays, most expert centres would rather base AD diagnosis on biomarkers (Jack et al., 2018), amnesia remains an important dimension in primary care settings, as investigations aiming to detect amyloid and tau pathologies are expensive and invasive.

However, the excessive confidence in the specificity of amnesia may also have negatively impacted the differential dementia diagnosis (Hornberger \& Piguet, 2012), as the presence of severe amnesia in frontotemporal lobar degeneration (FTLD), dementia with Lewy bodies (DLB), vascular dementia (VaD)(Elfrgen et al., 1993; Kraybill et al., 2005; Graham et al., 2005; Jicha et al., 2006; Reed et al., 2007; Mathias \& Burke, 2009; Hornberger et al., 2010; Hornberger et al., 2012; Yoshizawa et al., 2013; Bertoux et al., 2014; Petrova et al., 2015; Salmon et al., 2015) and psychiatric cases has been since reported (Kizilbash et al., 2002; Lee et al., 2012). Moreover, most of the studies assessing amnesia in AD lacked pathological confirmation (Pasquier et al., 2001; Sarazin et al., 2007; Teichmann et al., 2017). This issue is not trivial as describing the memory profile of clinically-defined AD raises a circular 
reasoning bias, contributing to overestimate the diagnostic accuracy of amnesia (Castilhos \& Chaves, 2017).

In this context, both hypothesis-free data-driven methods and clinicopathological correlation studies may provide new knowledge on both the clinical relevance of amnesia and the diagnostic value of memory tests such as the Free and Cued Selective Reminding Test (FCSRT) to predict AD pathology. The aim of this study was to use data-driven clustering on neuropathological data to test in an unbiased way the diagnostic value and accuracy of amnesia to predict $\mathrm{AD}$ among other neurodegenerative conditions. 


\section{Material and methods}

\subsection{Selection of participants (inclusion criteria)}

Patients were seen at referral (at first presentation) in a tertiary care memory clinic setting in Bordeaux, Lille, Marseille, Paris and Rouen. They had an initial Mini Mental State Examination (MMSE - Folstein et al., 1975) score $\geq 20 / 30$ during this first visit and a memory assessment with the FCSRT within six months of this initial visit. All were followed-up until death and received a diagnosis of dementia prior to death. They volunteered for brain donation (information was given regardless of the clinical presentation) and signed informed consents. On this basis, 91 patients were included. Patients had been followed-up at Lille $(87,4 \%)$, Paris $(9.5 \%)$, Rouen (1.9\%), Marseille (0.7\%) and Bordeaux (0.4\%) University Hospitals. Autopsies were performed between 1993 and 2017. Patients records were stored at the Lille brain bank (Lille Neurobank, Lille) and the Neuro-CEB brain bank.

\subsection{Standards Protocol Approvals, Registrations and Patient Consents}

The institutional review board of the Lille Neurobank of Lille University Hospital approved the study. All patients or their relatives signed written informed consent to participate in the study.

\subsection{Histopathologic procedures}

All cases underwent autopsy and neuropathologic examination by neuropathologists.

Postmortem delay ranged from 4 to 30 hours. Most of the right hemisphere was frozen for subsequent biochemical and molecular biology analysis. The whole left hemisphere, brainstem, cerebellum, and samples from the right hemisphere were fixed in $10 \%$ buffered formalin for histopathology and immunohistochemistry (tau protein, beta-amyloid, 
alphasynuclein, TDP-43, and prion protein). Tissue samples were taken from multiple cortical areas (Brodmann areas 4, 8/9, 10, 20/21, 38, 39, 40, 17, 18, 23, and 24), hippocampus, amygdala, nucleus basalis, basal ganglia, brainstem, cervical spinal cord, and cerebellum. Cerebrovascular scoring (including the semi quantification of arteriolosclerosis, amyloid angiopathy, perivascular space widening, myelin loss in the white matter, microinfarcts, and large infarcts) was made on 3 large coronal slides from the frontal lobe, the temporal lobe and basal ganglia region, after hematoxylin-eosin and Luxol fast blue staining (see Deramecourt et al., 2014). The clinical contribution of cerebrovascular lesions was considered as probable (vascular dementia or mixed dementia) in cases with a cerebrovascular score strictly above 10/20. Vascular lesions were evaluated as described before (Deramecourt et al., 2014); in our study, cases characterized by significant arterosclerosis will be noted $\mathrm{VaD}$ and amyloid angiopathy will be noted AA. Mixed pathology was systematically reported and involved the co-occurrence of two or more different pathologies. The respective pathological diagnostic criteria were used depending on the disease: AD (Hyman et al., 2012), DLB (McKeith et al., 2017), FTLD (Mackenzie et al., 2009) and Creuzfeldt-Jakob disease (CJD) (Budka et al., 1995).

\subsection{Clinical assessment}

The initial symptoms reported by patients or carers at presentation were encoded from the clinical records.

All participants underwent the French version of the FCSRT (Van der linden et al., 2004), which evaluates the ability to learn and recall a list of 16 written words. A first phase involves the learning of the words. During this phase, $4 \times 4$ groups of words were presented. Semantic cues were then given and participants had to associate the given cue (e.g. profession) to one of the 4 word presented (e.g. dentist) sequentially. Then, words were hidden and the semantic 
cues were used to control for memory encoding or immediate recall of the 4 words (e.g. "What was the profession?"). Memory recall is then evaluated by asking to retrieve the words, first spontaneously (free recall), then with the help of the semantic cues of a supraordinal taxonomic category for items that were not retrieved (cued recall). This phase is repeated twice. During these phases, if participants failed to retrieve the item with the category cue, they were reminded by presenting the cue and the item together. Total free recall and a total (free+cued) recall scores as well as an index of sensitivity to semantic cues ((total free recall score - total recall score)/(total recall score - 48)) are computed from this phase. Following a delay of 20-30 min, a final recall trial is performed, providing free, cued and total delayed recall scores.

General cognitive functioning was assessed with the Mattis Dementia Rating Scale (MDRS Mattis, 1988), an objective general cognitive battery widely used for the assessment of neurodegenerative conditions and staging of cognitive decline. The MDRS examines five cognitive domains (attention, initiation, construction, conceptualization, memory).

\subsection{Statistical analyses}

Statistical analyses were conducted with SPSS 20 (IBM, 2015). Univariate non-parametric (Kruskal-Wallis) ANOVA was used to assess group differences followed by Mann-Whitney test for two-by-two comparisons (or Chi-Squared test in case of binomial variables) because of non-normal data. Bonferroni corrections were applied to all statistical comparisons to correct for multiple comparisons. In order to determine the cluster architecture of memory performance in patients, a hierarchical clustering analysis using Ward's method was first employed on the standardized FCSRT's total scores (i.e. total free recall, total recall, sensitivity to cues and total delayed recall scores), based on Squared Euclidian Distance with a dendrogram examination. A Two-step clustering analysis based on a Bayesian Information 
Criteria was then used to match the different patients' clusters of memory performance to the histological diagnoses. In the first step, the Bayesian Information Criteria for each number of clusters within a specified range was performed and considered to find an initial estimate for the number of clusters. The second step refined the initial estimate by finding the greatest change in distance between the two closest clusters in each hierarchical clustering stage. Reports of the cluster analyses followed consensual recommendations (Clatworthy et al., 2005). As an analysis of the prediction value of the presence of absence of AD pathology, we employed binary logistic regression (Enter method). Akaike Information Criterion (AIC) was computed as an estimator of models' quality (lower AIC means higher quality) when the model prediction was significant. Receiver operating characteristic (ROC) curves were employed to identify patients with AD pathology based on each FCSRT score.

\section{Results}

\subsection{Study population}

On the whole population, the mean age at disease onset (age at first symptoms) was $65.07 \pm$ 9.84 years. The delay between symptoms onset and the first referral was $2.28 \pm 2.07$ years and the mean disease duration (from symptoms onset to death) was $9.05 \pm 4.46$ years. Three levels of education were categorised: primary (45.7\% of patients), high school (22.2\%) and graduate education (32.1\%). Initial MMSE score at presentation was $25.53 \pm 2.81$.

Final neuropathologic diagnoses consisted of 15 (16.5\%) pure AD, $26(28.6 \%)$ mixed AD and $50(54.9 \%)$ non-AD cases. Pure AD and mixed AD cases were all characterized by severe levels of neurofibrillary pathology (Braak stages $\geq 5$ ). Mixed AD (mAD) cases included $A D+V A D(n=9), A D+L B D(n=9), A D+F T L D(n=2), A D+A A(n=2)$ and $A D+\geq 2$ associated pathologies $(n=4)$. Non-AD cases were FTLD $(n=36), \operatorname{VaD}(n=9), \operatorname{CJD}(n=2)$ or mixed pathology such as LBD \& VaD $(n=3)$ cases. Six patients $(6.6 \%)$ had FTLD caused by a 
mutation in $G R N(\mathrm{n}=2)$ or $C 9 \operatorname{orf} 72(\mathrm{n}=4)$ genes. Mixed-AD patients were older than Pure-AD and Non-AD patients $(\mathrm{Z}=-3.218 ; \mathrm{p}=.001)$. Memory impairment reported at onset was more frequent in Mixed-AD in comparison to Non-AD $\left(\chi^{2}=8.483 ; \mathrm{p}=.004\right)$. Other variables were not statistically different across the three groups (all $\chi^{2}<6.5 ; \mathrm{p}>.02$ ) (Table 1 ). A single symptom was reported in $49.45 \%$ of cases, two symptoms were reported in $38.46 \%$ of cases and $\geq 3$ symptoms were reported in $6.59 \%$ of cases. In $5.49 \%$ of cases, first symptoms were missing from the records. At first visit, memory impairment was reported in $60.41 \%$ of patients, followed by behaviour and psychological symptoms (e.g. anxiety, sadness, hallucinations) in $27.47 \%$, language impairments $(24.17 \%)$, and motor symptoms $(7.69 \%)$. These symptoms were all based on carers reports.

\#Please insert Table 1 around here 


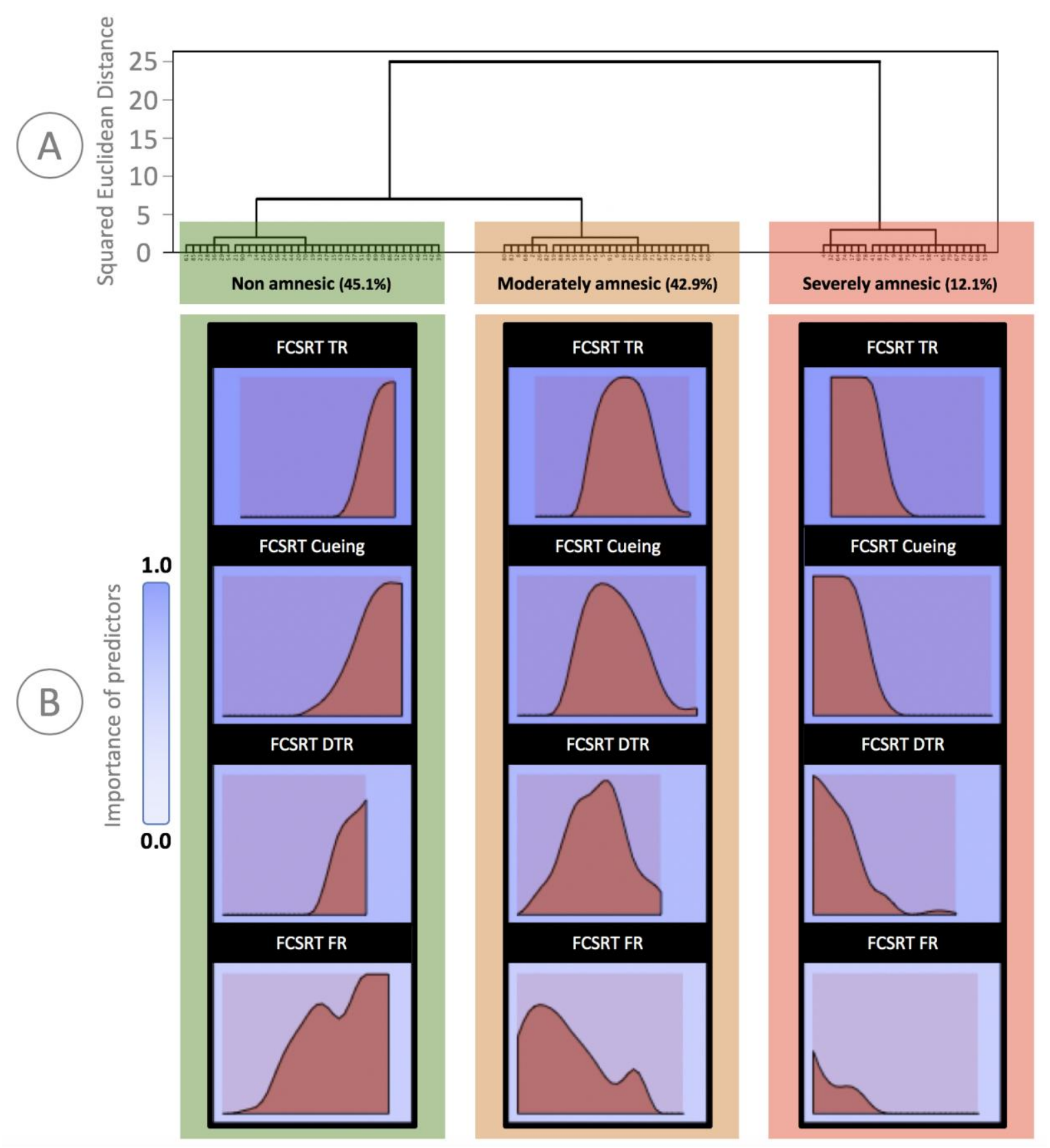

\subsection{Memory performance clustering (Figure 1.A; Table 2)}

The hierarchical clustering analysis revealed the existence of three clusters of patients: (1) non-amnesic (45.1\% of patients), (2) moderately amnesic (42.9\%) and (3) severely amnesic (12.1\%). This cluster architecture was validated independently with the memory score of the MDRS. There were significant differences between clusters $(F=12.470 ; p<.00005)$ on this memory score with the following pattern: non-amnesic > moderately amnesic $>$ severely amnesic. Importantly, when considering normative data of the FCSRT total recall score, none 
of the patients in the non-amnesic cluster could be considered as being amnesic. There were no differences between MMSE score $\left(\chi^{2}=3.261 ; \mathrm{p}=.19\right)$, age $\left(\chi^{2}=0.841 ; \mathrm{p}=.66\right)$, time to referral $\left(\chi^{2}=1.663 ; \mathrm{p}=.43\right)$ and gender $\left(\chi^{2}=4.531 ; \mathrm{p}=.10\right)$ between clusters. A non-significant statistical trend was observed on education $\left(\chi^{2}=10.431 ; \mathrm{p}=.005_{\text {uncorrected }}\right)$, with patients in the non-amnesic cluster having better education levels than those in the moderately $(Z=-2.733$; $\left.\mathrm{p}=.006_{\text {uncorrected }}\right)$ and severely amnesic clusters $\left(\mathrm{Z}=-2.378 ; \mathrm{p}=.025_{\text {uncorrected }}\right)$, the latter ones showing no differences between each other $(Z=-.799 ; p=.51)$. No interactions between the different variables were found.

\section{\#Please insert Table 2 around here}

\subsection{Matching between memory performance clusters and pathological diagnoses}

The two-step cluster analysis presented a good cluster quality (Silhouette coefficient $>.05$ ). As shown on Figure 1.B, FCSRT total recall has the best $(=1,00)$ inter-class predictor importance (indicating how well the variable can differentiate different clusters) followed by sensitivity to cues (.86), delayed total recall (.61) and free recall (.36). The "non-amnesic" cluster was composed of 41 patients including three (7.3\%) pure-AD, 10 (24.4\%) mixed-AD and $28(68.3 \%)$ non-AD patients. The "moderately amnesic" cluster was composed of 39 patients including $10(25.6 \%)$ pure-AD, 15 (38.5\%) mixed-AD and $14(35.9 \%)$ non-AD patients. The "severely amnesic" cluster was composed of 11 patients including two (18.2\%) pure-AD, one $(9.1 \%)$ mixed-AD and eight $(72.7 \%)$ non-AD patients. The distribution of diagnoses in the three clusters is presented on figure 2, table 2 and shows significant differences in the proportions of patients in each cluster for Pure-AD and Mixed-AD compared to Non-AD $\left(\chi^{2}=11.678 ; \mathrm{p}<.05\right)$. 


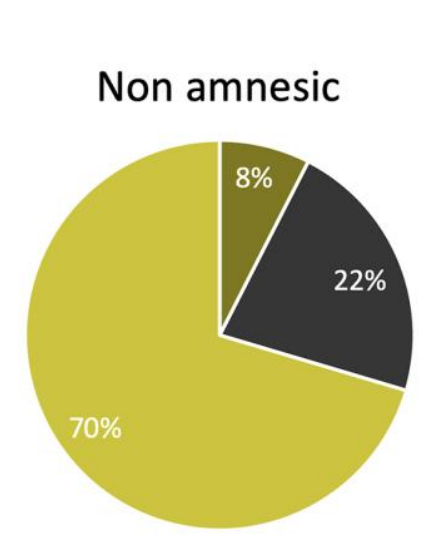

- pure-AD $\|$ mixed-AD $\backsim$ non-AD

\section{Moderately amnesic}

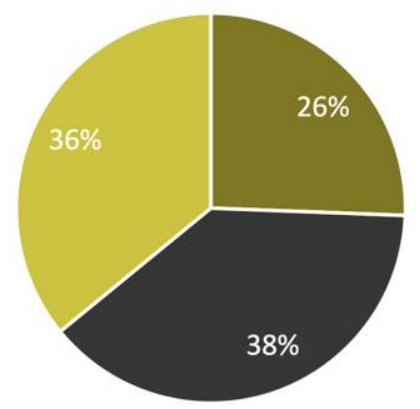

Severely amnesic

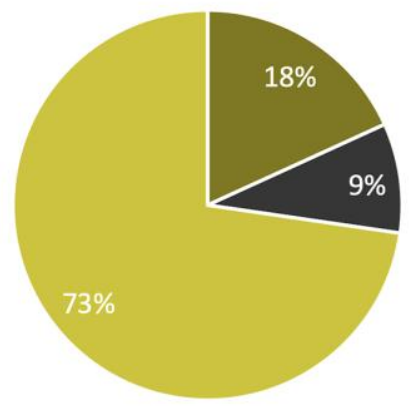

In order to provide a more detailed matching between the clusters and the pathological diagnoses, we divided the non-AD pathological diagnoses into FTLD, VaD and other pathologies (this last group including CJD and LBD mixed with $\mathrm{VaD}$ ) and crossed refined pathological diagnoses with the obtained memory clusters. A significant proportion of patients with non-AD pathology was either moderately or severely amnesic at presentation (44.4\% of FTLD, $55.6 \%$ of $\mathrm{VaD}$ and $20 \%$ of other pathologies patients) (table 3 ).

\section{\#Please insert Table 3 around here}

\subsection{Data-driven prediction of AD pathology}

We then used the FCSRT scores considered in the cluster analyses as a set of predictors for the presence of AD pathology in a binary logistic regression. The best data-driven prediction reached an accuracy of $70.3 \%\left(\chi^{2}=12.46 ; \mathrm{AIC}=118.79 ; \mathrm{p}<.05\right)$, meaning that the presence of AD pathology could only be correctly predicted in $70.3 \%$ of cases on the basis of the FCSRT four main scores. This model reached a sensitivity of $65.2 \%$ and a specificity of $75.6 \%$, with a positive predictive value of $73.2 \%$ and $17.6 \%$ of cases being identified as false positive cases (16/91 patients). In order to evaluate the capacity of each FCRST score to discriminate cases with $\mathrm{AD}$ pathology from those without $\mathrm{AD}$ pathology, optimal receiver operating 
characteristic curves were computed. Optimum areas under the curve (AUC) were defined using the highest Youden index (optimizing both sensitivity and specificity of diagnosis). AUC for free recall (.390), total recall (.377), sensitivity to cues (.391) and delayed total recall (.400) were low. Only total recall $(p=.028)$ and sensitivity to cues $(p=.045)$ were significant discriminants.

We then sought to determine whether the FCSRT prediction of AD pathology was similar when analyses were restricted to patients for which memory impairment was the main complaint at presentation. The prediction accuracy reached $66.7 \%\left(\chi^{2}=8.314 ; \mathrm{p}=.08\right)$, increasing the initial sensitivity to $83.9 \%$ and decreasing the specificity to $43.5 \%(24.1 \%$ of false positive cases in this sample, or 13/54 patients) in comparison with the data-driven prediction of AD pathology ( $-3.7 \%$ of accuracy, $+18,7 \%$ of sensitivity, $-32.1 \%$ of specificity).

\section{Discussion}

The aim of this study was to assess the predictive value of amnesia for $\mathrm{AD}$ among 91 patients examined in the early stages of cognitive decline and followed until autopsy. We based our investigations on the FCSRT, a reference tool to explore the different components of verbal memory (Grober \& Buschke, 1987; Van der Linden et al., 2004). Using an unbiased datadriven approach, we studied the correspondence between FCSRT memory profiles and the pathological diagnoses. The predictive value of the FCSRT for AD was assessed as well. In this study, the use of the FCSRT, relying on semantic cues during learning and recall, allowed to identify "pure" amnesia among the patients, i.e. a typical impairment of memory storage and not only difficulties in retrieval processes. Data-driven clustering revealed three distinct clusters of performance reflecting different levels of amnesia. However, there was little correspondence between these clusters and AD pathology, since a third of patients with pure 
and mixed AD pathology were non-amnesic at presentation and nearly half of patients devoid of $\mathrm{AD}$ pathology were amnesic. In addition, data-driven prediction of $\mathrm{AD}$ pathology based on FCSRT scores had only a low accuracy $(70.3 \%)$.

Overall, the findings of this study suggest that despite its usefulness to identify amnesia, the FCSRT is of limited value to specifically diagnose AD pathology. Our results show that this symptom is too frequently observed in other diseases to accurately support the clinical diagnosis of AD. While discussing the neural mechanisms at stake in amnesia is outside the scope of our study, we think that the implicit association between amnesia, AD and hippocampus degeneration led to the common belief that amnesia is a specific symptom of $\mathrm{AD}$, which is still vividly present in clinical practice and scientific literature (Sarazin et al., 2007; Teichmann et al., 2017; Jahn, 2013; Maruszak \& Thuret, 2014). Indeed, progressive pathological changes due to AD are now well characterized. Since the early 1990s, the hippocampus complex is known to be affected early during the course of the disease (Braak \& Braak, 1997; Craig et al., 2011). Years before, identification and characterization of memory deficits after bilateral surgical lesions of the mesial temporal lobe demonstrated the importance of the hippocampus in memory processing (Squire, 2004). The hippocampal complex was then established as the core anatomical component of the declarative memory system (Squire, 2004). As highlighted by others (Aggleton et al., 2016), the historical assumption that the medial temporal lobe is the key structure for episodic memory has contributed to link memory loss in AD to the hippocampus complex, leading some to consider AD as a hippocampal dementia (Craig et al., 2011). In this context, tests assessing episodiclike memory, thought to assess the function of the hippocampus complex, have been increasingly used as an early marker of AD and amnesia was eventually considered as the core clinical feature of typical AD. This overlap between amnesia, AD and hippocampal 
dysfunctions led some authors to hypothesize the existence of an "amnestic syndrome of hippocampal type" (Dubois et al., 2004; Sarazin et al., 2007; Xie et al., 2014) or in other words, a cognitive syndrome characterized by memory storage difficulties due to hippocampal atrophy, that would be specific to AD. Cued memory paradigms and the FCSRT in particular, were then subsequently used to track the conversion from MCI to AD (Sarazin et al., 2007), as well as for the positive (Dubois et al., 2004, 2014; Xie et al., 2014) and differential diagnosis of AD (Pasquier et al., 2001; Teichmann et al., 2017; Lemos et al., 2014).

Our findings set limitations to this approach. Using a data-driven clustering method, we were able to divide our population into three groups with absent, moderate and severe amnesia according to the FCSRT memory scores obtained at an early stage of cognitive decline. However, there was a limited correspondence with AD pathology. In the severely amnesic cluster, non-AD patients were three times as much as AD patients. Nearly half of patients with FTLD and $\mathrm{VaD}$ patients were classified in the amnesic clusters. There is however an ambiguity regarding whether amnesia should be considered as a marker of AD pathology (Dubois et al., 2014) or typical AD (Sarazin et al., 2007), i.e. AD with an amnesic presentation. To take the latter into account, we then restricted the analysis to patients with memory complaint at presentation. Both approaches showed a similarly poor accuracy of FCSRT to predict AD, showing that our results were not biased by an over-representation of atypical $\mathrm{AD}$ cases. These findings are in line with previous reports made on cohorts with a pathological confirmation of diagnoses. Indeed, numerous studies suggested that severe amnesia could be observed in patients with non-AD or mixed AD pathology, such as DLB (Kraybill et al., 2005; Yoshizawa et al., 2013; Salmon et al., 2015), FTLD (Elgren et al., 1993; Grahan et al., 2005; Hornberger et al., 2012), or to a lesser degree VaD (Jicha et al., 
2006; Reed et al., 2007). This last decade, memory impairment was reported in clinicallydefined DLB (Petrova et al., 2015; Molano et al., 2010), in the clinical subtypes of FTLD such as behavioural variant frontotemporal dementia (Hornberger et al., 2010; Bertoux et al., 2014), semantic progressive aphasia (Casaletto et al., 2017), non-fluent progressive aphasia (Ramanan et al., 2016), amyotrophic lateral sclerosis (Mantovan et al., 2003), progressive supranuclear palsy (Kobylecki et al., 2015) as well as in clinically-defined VaD (Mathias \& Burke, 2009) although inconsistent findings were reported in this disease due to the variable topography of vascular lesions. Not least of all, severe amnesia is also the main feature of hippocampal sclerosis, often related to aberrant TDP-43 immunohistochemistry (Nelson et al., 2019). Limbic-predominant age-related TDP-43 encephalopathy (LATE) with or without hippocampal sclerosis affects $20 \%$ to $50 \%$ of individuals past age 80 years, according to large community-based autopsy series (reviewed in Nelson et al., 2019). The recent recognition of LATE as one of the common age-related diseases that can mimic the amnestic presentation of AD hence came as a major breakthrough (Nelson et al., 2013), demonstrating that AD is not the sole cause of amnesia, even in the 'oldest old'.

Taken together, these reports and our findings plead against the exclusivity of amnesia to AD. Amnesia should be conceived as a common symptom of neurodegenerative disease, rather than a reliable indication of $\mathrm{AD}$ pathology.

This study is the first to specifically investigate the accuracy of amnesia to predict AD pathology in a cohort with various pathologically confirmed aetiologies. While we believe that the reasonable sample size, the inclusion of patients at early or mild dementia stages, the use of the FCSRT at presentation as well as the utilization of data-driven procedures are strengths to this study, we also acknowledge some limitations. In particular, our cohort may not be representative of all patients with progressive neurocognitive disorders. The patients 
included in this study were seen in tertiary centres and therefore, may be more atypical. Indeed, the proportion of pure-AD patients is smaller than the proportion of non-AD patients, the age of onset is younger than usual cohorts and the gender ratio is atypical in the AD group. This particular recruitment might have led to an underrepresentation of typical amnesic $\mathrm{AD}$ and an overrepresentation of atypical patients, such as non-amnesic $\mathrm{AD}$ and amnesic nonAD patients. Although the majority of patients were recruited from a centre where information on the possibility of brain donation is given very widely, regardless of the atypical presentation, one cannot exclude that patients and families are more willing to brain autopsy when the clinical diagnosis has been debated. However, the ancillary analysis on the subset of patients that had memory complaints at first referral (simulating the commonest context in which the presence of AD pathology is suspected) showed similar prediction accuracy with the analysis conducted in the whole population.

Because a single test was employed to assess the presence of amnesia in this study, one could question the generalization of our findings and argue that different tests could have led to different results. This is a relevant question given that previous studies have shown the marginal ability of the FCSRT to distinguish clinical AD from behavioural variant of FTLD in particular (Bertoux et al., 2014). Indeed, FTLD cases represented $72 \%$ of non-AD cases in this study, and among them, $64 \%$ received a clinical diagnosis of a behavioural variant FTLD and $14 \%$ a clinical diagnosis of $\mathrm{AD}$. Among $\mathrm{AD}$ cases, $13 \%$ received a clinical diagnosis of behavioural variant FTLD. First, we believe that considering a single rather than several verbal memory tests is an approach that is closer to the clinical practice, where time is limited and other cognitive domains have to be assessed, although the best practice would have been to combine our exploration with another (e.g. spatial) qualitatively different measure of memory. The FCSRT is commonly used by neuropsychologists as it involved both free and 
cued-based recalls, thus allowing us to tackle the commonest criticize made to studies only addressing free recall. In addition, the poor discrimination power of memory testing in the context of the differential diagnosis between AD and FTLD, although it was never the focus of a neuropathological study before, has been shown independently of the test used and the memory component explored (Bertoux et al. 2018; Poos et al., 2018). In consequence, we believe that it is likely that our findings could be generalizable with other common verbal memory assessment. However, given that the prediction accuracy was only based on a single memory test, we cannot rule out that only the sensitivity and specificity to AD of verbal amnesia, and not amnesia in general, have been explored in our study.

The approach to consider a single measure raises another point of discussion: whether or not, in specialized memory clinics, memory assessment is considered alone to inform diagnostic decisions. To this question, the definitive answer is no, as neuropsychologists and specialized neurologists would rather consider a general behavioural and neuropsychological profile relying on multiple cognitive domains. We thus acknowledge that our approach, relying on a single measure to predict the underlying pathology, does not realistically fit the clinical practices occurring in specialized centres - although it was not the aim of this study to do so. As mentioned above, the implicit association between amnesia, AD and hippocampus degeneration led to the common belief that amnesia is a specific symptom of AD. In that perspective, medical tests based on shortened version of the FCSRT have been used increasingly by physicians outside specialized centres in the last years to screen for AD specifically (Cowppli-Bony et al. 2005). Our findings, showing that verbal amnesia is a common symptom of neurodegenerative diseases and therefore does not predict AD pathology specifically, contradict what likely became over the year a clinical heuristic commonly used by clinicians. What is at stake here is not a shift in expert centres' practices, but rather higher caution warranted outside specialized centres, where the diagnosis relies on 
less exams and expertise. To follow the best neuropsychological practices, future studies that would aim to replicate our findings should consider the FCSRT - or any other verbal episodic-like memory test - together with another qualitatively different memory measure (such as visual or spatial memory).

This study has important implications for the early diagnosis. Early diagnosis offers the opportunity for timely interventions, coordinated care plans and better management of symptoms. Experts agree to consider early diagnosis a cost-saving approach, through a reduction in preventable hospitalization, simplification of the medication regimen and postponement of institutionalization (Alzheimer's Association, 2018). However, a correct diagnosis is paramount to allocate healthcare resources in an equitable and cost-effective fashion. In that regard, clinical diagnosis of AD is not sufficiently accurate: up to $50 \%$ of patients with mild cognitive impairment and $25 \%$ of those with mild dementia recruited in AD clinical trials do not meet biomarker criteria for AD (Sevigny et al., 2016). Differential $\mathrm{AD}$ diagnosis is highly relevant since pharmacotherapy and prognosis differ in AD mimics. Our findings thus support the use of CSF and imaging biomarkers (Jack et al., 2018). However, a thorough diagnostic workup is still a costly venture. It can reach up to $\$ 5000$ in the early stages, assuming all available diagnostic procedures are done (Winblad et al., 2016), a difficult cost to sustain for most healthcare systems, even when counterbalancing the putative long-term economies. Improving the accuracy of early clinical diagnosis is therefore an outstanding issue. We herein demonstrate that AD clinical diagnosis cannot rely solely on the memory profile or severity of amnesia. This highlights the importance to examine behaviour and other cognitive domains in addition to memory during a diagnosis-oriented neuropsychological assessment or screening (Albert et al., 2011). What is also highlighted here is the common limitations of current memory assessment in the field of 
neurodegeneration. Limited ecological validity of word-list based tests and their lack of an episodic character should be considered as well as other novel or unexplored cognitive processes to take up the biggest challenge of modern neuropsychology within our field: providing a set of measures able to accurately predict the underlying pathology. This "molecular neuropsychology" should go way beyond classical tasks and classical assumption of specific impairments. By summing up the past findings and bringing a pathological confirmation of the non-specificity of memory impairment to $\mathrm{AD}$, we believe that the current study participated in this fresh start.

\section{Acknowledgement, Conflict \& Funding Sources}

This study has been developed and supported by the laboratory of excellence (LABEX) DISTALZ (Development of Innovative Strategies for a Transdisciplinary approach to ALZheimer's disease), the National Reference Centre for Young Alzheimer's patients (CNRMAJ) and the Lille Centre of Excellence for Neurodegenerative Disorders (LICEND). The authors report no disclosure relevant to the manuscript. The authors also thank the “NeuroCEB” Brain Bank (GIE Neuro-CEB BB-0033-00011), funded by a consortium of patient associations: ARSEP (association for research on multiple sclerosis), CSC (association for research on cerebellar ataxias), France Parkinson, France Alzheimer and LECMA-Vaincre Alzheimer. The NeuroCEB Brain bank network includes: Prof. Franck Letournel (CHU Angers), Prof. Anne Vital (CHU Bordeaux), Prof. Françoise Chapon (CHU Caen), Dr. Catherine Godfraind (CHU Clermont-Ferrand), Prof. Claude-Alain Maurage (CHU Lille), Dr. Vincent Deramecourt (CHU Lille), Dr. David Meyronnet (CHU Lyon), Dr. Nathalie Streichenberger (CHU Lyon), Dr. André Maues de Paula (CHU Marseille), Dr. Valérie Rigau (CHU Montpellier), Dr. Fanny Vandenbos-Burel (Nice), Prof. Charles Duyckaerts (CHU PS Paris), Prof. Danielle Seilhean (CHU PS, Paris), Dr. Véronique Sazdovitch (CHU PS Paris), 
Dr. Serge Milin (CHU Poitiers), Dan Christian Chiforeanu (CHU Rennes), Prof. Annie Laquerrière (CHU Rouen), Dr. Béatrice Lannes (CHU Strasbourg). Dr. Bertoux is supported by the Région Haut de France and the Planiol Foundation. 


\section{References}

Aggleton JP, Pralus A, Nelson AJ, Hornberger M. Thalamic pathology and memory loss in early Alzheimer's disease: moving the focus from the medial temporal lobe to Papez circuit. Brain. 2016 Jul;139(Pt 7):1877-90.

Albert MS, DeKosky ST, Dickson D, Dubois B, Feldman HH, Fox NC, Gamst A, Holtzman DM, Jagust WJ, Petersen RC, Snyder PJ, Carrillo MC, Thies B, Phelps CH. The diagnosis of mild cognitive impairment due to Alzheimer's disease: recommendations from the National Institute on Aging-Alzheimer's Association workgroups on diagnostic guidelines for Alzheimer's disease. Alzheimers Dement. 2011 May;7(3):270-9.

Bertoux M, de Souza LC, Corlier F, Lamari F, Bottlaender M, Dubois B, Sarazin M. Two distinct amnesic profiles in behavioral variant frontotemporal dementia. Biol Psychiatry. 2014 Apr 1;75(7):582-8.

Bertoux M, Flanagan EC, Hobbs M, Ruiz-Tagle A, Delgado C, Miranda M, Ibáñez A, Slachevsky A, Hornberger M. Structural Anatomical Investigation of Long-Term Memory Deficit in Behavioral Frontotemporal Dementia. J Alzheimers Dis. 2018;62(4):1887-1900.

Braak H, Braak E. Frequency of stages of Alzheimer-related lesions in different age categories. Neurobiol Aging. 1997 Jul-Aug;18(4):351-7.

Budka H, Aguzzi A, Brown P, Brucher JM, Bugiani O, Gullotta F, Haltia M, Hauw JJ, Ironside JW, Jellinger K, et al. Neuropathological diagnostic criteria for Creutzfeldt-Jakob 
disease (CJD) and other human spongiform encephalopathies (prion diseases). Brain Pathol. 1995 Oct;5(4):459-66.

Casaletto KB, Marx G, Dutt S, Neuhaus J, Saloner R, Kritikos L, Miller B, Kramer JH. Is "Learning" episodic memory? Distinct cognitive and neuroanatomic correlates of immediate recall during learning trials in neurologically normal aging and neurodegenerative cohorts. Neuropsychologia. 2017 Jul 28;102:19-28.

Castilhos RM, Chaves ML. Free and Cued Selective Reminding Test sensitivity. Alzheimers Dement (Amst). 2017 Nov 26;10:75.

Clatworthy J, Buick D, Hankins M, Weinman J, Horne R. The use and reporting of cluster analysis in health psychology: a review. Br J Health Psychol. 2005 Sep;10(Pt 3):329-58.

Cowppli-Bony P, Fabrigoule C, Letenneur L, Ritchie K, Alpérovitch A, Dartigues JF, Dubois B. Validity of the five-word screening test for Alzheimer's disease in a population based study. Rev Neurol (Paris). 2005 Dec;161(12 Pt 1):1205-12.

Craig LA, Hong NS, McDonald RJ. Revisiting the cholinergic hypothesis in the development of Alzheimer's disease. Neurosci Biobehav Rev. 2011 May;35(6):1397-409.

Deramecourt V, Slade JY, Oakley AE, Perry RH, Ince PG, Maurage CA, Kalaria RN. Staging and natural history of cerebrovascular pathology in dementia. Neurology. 2012 Apr 3;78(14):1043-50. 
Dubois B, Albert ML. Amnesic MCI or prodromal Alzheimer's disease? Lancet Neurol. 2004 Apr;3(4):246-8.

Dubois B, Feldman HH, Jacova C, Hampel H, Molinuevo JL, Blennow K, DeKosky ST, Gauthier S, Selkoe D, Bateman R, Cappa S, Crutch S, Engelborghs S, Frisoni GB, Fox NC, Galasko D, Habert MO, Jicha GA, Nordberg A, Pasquier F, Rabinovici G, Robert P, Rowe C, Salloway S, Sarazin M, Epelbaum S, de Souza LC, Vellas B, Visser PJ, Schneider L, Stern Y, Scheltens P, Cummings JL. Advancing research diagnostic criteria for Alzheimer's disease: the IWG-2 criteria. Lancet Neurol. 2014 Jun;13(6):614-29.

Elfgren C, Passant U, Risberg J. Neuropsychological findings in frontal lobe dementia. Dementia. 1993 May-Aug;4(3-4):214-9.

Folstein MF, Folstein SE, McHugh PR. "Mini-mental state". A practical method for grading the cognitive state of patients for the clinician. J Psychiatr Res. 1975 Nov;12(3):189-98.

Graham A, Davies R, Xuereb J, Halliday G, Kril J, Creasey H, Graham K, Hodges J. Pathologically proven frontotemporal dementia presenting with severe amnesia. Brain. 2005 Mar;128(Pt 3):597-605.

Grober E, Buschke H. Genuine memory deficits in dementia. Developmental Neuropsychology. 1987, 3(1), 13-36.

Hornberger M, Piguet O. Episodic memory in frontotemporal dementia: a critical review. Brain. 2012 Mar;135(Pt 3):678-92. 
Hornberger M, Piguet O, Graham AJ, Nestor PJ, Hodges JR. How preserved is episodic memory in behavioral variant frontotemporal dementia? Neurology. 2010 Feb 9;74(6):472-9.

Hornberger M, Wong S, Tan R, Irish M, Piguet O, Kril J, Hodges JR, Halliday G. In vivo and post-mortem memory circuit integrity in frontotemporal dementia and Alzheimer's disease. Brain. 2012 Oct;135(Pt 10):3015-25.

Hyman BT, Phelps CH, Beach TG, Bigio EH, Cairns NJ, Carrillo MC, Dickson DW, Duyckaerts C, Frosch MP, Masliah E, Mirra SS, Nelson PT, Schneider JA, Thal DR, Thies B, Trojanowski JQ, Vinters HV, Montine TJ. National Institute on Aging-Alzheimer's Association guidelines for the neuropathologic assessment of Alzheimer's disease. Alzheimers Dement. 2012 Jan;8(1):1-13.

Jack CR Jr, Bennett DA, Blennow K, Carrillo MC, Dunn B, Haeberlein SB, Holtzman DM, Jagust W, Jessen F, Karlawish J, Liu E, Molinuevo JL, Montine T, Phelps C, Rankin KP, Rowe CC, Scheltens P, Siemers E, Snyder HM, Sperling R. NIA-AA Research Framework: Toward a biological definition of Alzheimer's disease. Alzheimers Dement. 2018 Apr;14(4):535-562.

Jahn H. Memory loss in Alzheimer's Disease. Dialogues Clin Neurosci. 2013 Dec; 15(4) : $445-454$

Jicha GA, Petersen RC, Knopman DS, Boeve BF, Smith GE, Geda YE, Johnson KA, Cha R, Delucia MW, Braak H, Dickson DW, Parisi JE. Argyrophilic grain disease in demented 
subjects presenting initially with amnesic mild cognitive impairment. J Neuropathol Exp Neurol. 2006 Jun;65(6):602-9.

Kizilbash AH, Vanderploeg RD, Curtiss G. The effects of depression and anxiety on memory performance. Arch Clin Neuropsychol. 2002 Jan;17(1):57-67.

Kobylecki C, Jones M, Thompson JC, Richardson AM, Neary D, Mann DM, Snowden JS, Gerhard A. Cognitive-behavioural features of progressive supranuclear palsy syndrome overlap with frontotemporal dementia. J Neurol. 2015;262(4):916-22.

Kraybill ML, Larson EB, Tsuang DW, Teri L, McCormick WC, Bowen JD, Kukull WA, Leverenz JB, Cherrier MM. Cognitive differences in dementia patients with autopsy-verified AD, Lewy body pathology, or both. Neurology. 2005 Jun 28;64(12):2069-73.

Lee RS, Hermens DF, Porter MA, Redoblado-Hodge MA. A meta-analysis of cognitive deficits in first-episode Major Depressive Disorder. J Affect Disord. 2012 Oct;140(2):113-24.

Lemos R, Duro D, Simões MR, Santana I. The free and cued selective reminding test distinguishes frontotemporal dementia from Alzheimer's disease. Arch Clin Neuropsychol. 2014 Nov;29(7):670-9.

Mackenzie IR, Neumann M, Bigio EH, Cairns NJ, Alafuzoff I, Kril J, Kovacs GG, Ghetti B, Halliday G, Holm IE, Ince PG, Kamphorst W, Revesz T, Rozemuller AJ, Kumar-Singh S, Akiyama H, Baborie A, Spina S, Dickson DW, Trojanowski JQ, Mann DM. Nomenclature 
for neuropathologic subtypes of frontotemporal lobar degeneration: consensus recommendations. Acta Neuropathol. 2009 Jan;117(1):15-8.

Mantovan MC, Baggio L, Dalla Barba G, Smith P, Pegoraro E, Soraru' G, Bonometto P, Angelini C. Memory deficits and retrieval processes in ALS. Eur J Neurol. 2003 May;10(3):221-7.

Maruszak A \& Thuret S. Why looking at the whole hippocampus is not enough-a critical role for anteroposterior axis, subfield and activation analyses to enhance predictive value of hippocampal changes for Alzheimer's disease diagnosis. Front Cell Neurosci. 2014; 8: 95.

Mathias JL, Burke J. Cognitive functioning in Alzheimer's and vascular dementia: a metaanalysis. Neuropsychology. 2009 Jul;23(4):411-23.

Mattis S. Dementia Rating Scale. Professional manual. Florida: Psychological Assessment Resources; 1988.

McKhann GM, Knopman DS, Chertkow H, Hyman BT, Jack CR Jr, Kawas CH, Klunk WE, Koroshetz WJ, Manly JJ, Mayeux R, Mohs RC, Morris JC, Rossor MN, Scheltens P, Carrillo MC, Thies B, Weintraub S, Phelps CH. The diagnosis of dementia due to Alzheimer's disease: recommendations from the National Institute on Aging-Alzheimer's Association workgroups on diagnostic guidelines for Alzheimer's disease. Alzheimers Dement. 2011 May;7(3):263-9. 
McKeith IG, Boeve BF, Dickson DW, Halliday G, Taylor JP, Weintraub D, Aarsland D, Galvin J, Attems J, Ballard CG, Bayston A, Beach TG, Blanc F, Bohnen N, Bonanni L, Bras J, Brundin P, Burn D, Chen-Plotkin A, Duda JE, El-Agnaf O, Feldman H, Ferman TJ, Ffytche D, Fujishiro H, Galasko D, Goldman JG, Gomperts SN, Graff-Radford NR, Honig LS, Iranzo A, Kantarci K, Kaufer D, Kukull W, Lee VMY, Leverenz JB, Lewis S, Lippa C, Lunde A, Masellis M, Masliah E, McLean P, Mollenhauer B, Montine TJ, Moreno E, Mori E, Murray M, O'Brien JT, Orimo S, Postuma RB, Ramaswamy S, Ross OA, Salmon DP, Singleton A, Taylor A, Thomas A, Tiraboschi P, Toledo JB, Trojanowski JQ, Tsuang D, Walker Z, Yamada M, Kosaka K. Diagnosis and management of dementia with Lewy bodies: Fourth consensus report of the DLB Consortium. Neurology. 2017 Jul 4;89(1):88-100.

Molano J, Boeve B, Ferman T, Smith G, Parisi J, Dickson D, Knopman D, Graff-Radford N, Geda Y, Lucas J, Kantarci K, Shiung M, Jack C, Silber M, Pankratz VS, Petersen R. Mild cognitive impairment associated with limbic and neocortical Lewy body disease: a clinicopathological study. Brain. 2010 Feb;133(Pt 2):540-56.

Nelson PT, Smith CD, Abner EL, Wilfred BJ, Wang WX, Neltner JH, Baker M, Fardo DW, Kryscio RJ, Scheff SW, Jicha GA, Jellinger KA, Van Eldik LJ, Schmitt FA. Hippocampal sclerosis of aging, a prevalent and high-morbidity brain disease. Acta Neuropathol. 2013 Aug;126(2):161-77.

Nelson PT, Dickson DW, Trojanowski JQ, Jack CR, Boyle PA, Arfanakis K, Rademakers R, Alafuzoff I, Attems J, Brayne C, Coyle-Gilchrist ITS, Chui HC, Fardo DW, Flanagan ME, Halliday G, Hokkanen SRK, Hunter S, Jicha GA, Katsumata Y, Kawas CH, Keene CD, Kovacs GG, Kukull WA, Levey AI, Makkinejad N, Montine TJ, Murayama S, Murray ME, 
Nag S, Rissman RA, Seeley WW, Sperling RA, White Iii CL, Yu L, Schneider JA. (2019). Limbic-predominant age-related TDP-43 encephalopathy (LATE): consensus working group report. Brain.

Pasquier F, Grymonprez L, Lebert F, Van der Linden M. Memory impairment differs in frontotemporal dementia and Alzheimer's disease. Neurocase. 2001;7(2):161-71.

Petrova M, Mehrabian-Spasova S, Aarsland D, Raycheva M, Traykov L. Clinical and Neuropsychological Differences between Mild Parkinson's Disease Dementia and Dementia with Lewy Bodies. Dement Geriatr Cogn Dis Extra. 2015 May 29;5(2):212-20.

Poos JM, Jiskoot LC, Papma JM, van Swieten JC, van den Berg E. Meta-analytic Review of Memory Impairment in Behavioral Variant Frontotemporal Dementia. J Int Neuropsychol Soc. 2018 Jul;24(6):593-605.

Ramanan S, Flanagan E, Leyton CE, Villemagne VL, Rowe CC, Hodges JR, Hornberger M. Non-Verbal Episodic Memory Deficits in Primary Progressive Aphasias are Highly Predictive of Underlying Amyloid Pathology. J Alzheimers Dis. 2016;51(2):367-76.

Reed BR, Mungas DM, Kramer JH, Ellis W, Vinters HV, Zarow C, Jagust WJ, Chui HC. Profiles of neuropsychological impairment in autopsy-defined Alzheimer's disease and cerebrovascular disease. Brain. 2007 Mar;130(Pt 3):731-9. 
Salmon DP, Heindel WC, Hamilton JM, Vincent Filoteo J, Cidambi V, Hansen LA, Masliah

E, Galasko D. Recognition memory span in autopsy-confirmed Dementia with Lewy Bodies and Alzheimer's Disease. Neuropsychologia. 2015 Aug;75:548-55.

Sarazin M, Berr C, De Rotrou J, Fabrigoule C, Pasquier F, Legrain S, Michel B, Puel M, Volteau M, Touchon J, Verny M, Dubois B. Amnesic syndrome of the medial temporal type identifies prodromal AD: a longitudinal study. Neurology. 2007 Nov 6;69(19):1859-67.

Sevigny J, Suhy J, Chiao P, Chen T, Klein G, Purcell D, Oh J, Verma A, Sampat M, Barakos J. Amyloid PET screening for enrichment of early-stage Alzheimer disease clinical trials: experience in a phase 1b clinical trial. Alzheimer Dis. Assoc. Disord. 30, 1-7(2016)

Squire LR. Memory systems of the brain: a brief history and current perspective. Neurobiol Learn Mem. 2004 Nov;82(3):171-7.

Teichmann M, Epelbaum S, Samri D, Levy Nogueira M, Michon A, Hampel H, Lamari F, Dubois B. Free and Cued Selective Reminding Test - accuracy for the differential diagnosis of Alzheimer's and neurodegenerative diseases: A large-scale biomarker-characterized monocenter cohort study (ClinAD). Alzheimers Dement. 2017 Aug;13(8):913-923.

Van der Linden M, Coyette F, Poitrenaud J et al. L'épreuve de rappel libre/rappel indicé à 16 items (RL/RI-16). In: Van der Linden M, et les membres du GREMEM, editors. L'évaluation des troubles de la mémoire: présentation de quatre tests de mémoire épisodique avec leur étalonnage. Marseille: Solal; 2004. p. 25-47. 
Winblad B, Amouyel P, Andrieu S, Ballard C, Brayne C, Brodaty H, Cedazo-Minguez A, Dubois B, Edvardsson D, Feldman H, Fratiglioni L, Frisoni GB, Gauthier S, Georges J, Graff C, Iqbal K, Jessen F, Johansson G, Jönsson L, Kivipelto M, Knapp M, Mangialasche F, Melis R, Nordberg A, Rikkert MO, Qiu C, Sakmar TP, Scheltens P, Schneider LS, Sperling R, Tjernberg LO, Waldemar G, Wimo A, Zetterberg H. Defeating Alzheimer's disease and other dementias: a priority for European science and society. Lancet Neurol. 2016 15(5), 455-532.

Xie J, Gabelle A, Dorey A, Garnier-Crussard A, Perret-Liaudet A, Delphin-Combe F, et al. Initial memory deficit profiles in patients with a cerebrospinal fluid Alzheimer's disease signature. J Alzheimers Dis. 2014;41(4):1109-16.

Yoshizawa H, Vonsattel JP, Honig LS. Early neuropsychological discriminants for Lewy body disease: an autopsy series. J Neurol Neurosurg Psychiatry. 2013 Dec;84(12):1326-30. 


\begin{tabular}{|c|c|c|c|}
\hline & Pure-AD & Mixed-AD & Non-AD \\
\hline Age & $69.7(10.9)$ & $71.9(7.3) *$ & $65.1(9.9)$ \\
\hline \multirow[t]{2}{*}{ Gender (W/M) } & $46.7 \% /$ & $53.8 \% /$ & $24 \% / 76 \%$ \\
\hline & $53.3 \%$ & $46.2 \% *$ & \\
\hline \multicolumn{4}{|l|}{ Level of education } \\
\hline Primary & $33.3 \%$ & $52.0 \%$ & $44.9 \%$ \\
\hline Secondary & $26.7 \%$ & $20.0 \%$ & $28.6 \%$ \\
\hline Graduate & $40.0 \%$ & $28.0 \%$ & $26.5 \%$ \\
\hline Time (years) to referral & $2.6(2.5)$ & $2.1(2.5)$ & $2.5(2.2)$ \\
\hline Total (years) disease & $11.07(5.3)$ & $8.2(4.1)$ & $8.8(4.3)$ \\
\hline \multicolumn{4}{|l|}{ duration } \\
\hline MMSE & $25.7(2.2)$ & $24.7(2.9)$ & $25.9(2.9)$ \\
\hline \multicolumn{4}{|c|}{ Initial symptoms reported by carers } \\
\hline Memory impairment & $66.6 \%$ & $73.1 \% *$ & $54.0 \%$ \\
\hline Behavioral and & $26.7 \%$ & $19.2 \%$ & $30.0 \%$ \\
\hline \multicolumn{4}{|l|}{ psychological } \\
\hline \multicolumn{4}{|l|}{ symptoms } \\
\hline Language impairment & $26.7 \%$ & $11.5 \%$ & $30.0 \%$ \\
\hline Motor symptoms & $0.0 \%$ & $7.7 \%$ & $10.0 \%$ \\
\hline
\end{tabular}

Table 1 - Demographics, Mini Mental State Examination (MMSE) score and initial symptoms reported by careers at presentation. * Significant difference with Non-AD

\begin{tabular}{|l|c|c|c|c|} 
Clusters & Total Free & Total Recall & Cueing (\%) & Delayed Total \\
\hline
\end{tabular}




\begin{tabular}{|c|c|c|c|c|}
\hline & Recall (/48) & $(/ 48)$ & & Recall (/16) \\
\hline Non-Amnesic & $20.27 \pm 6.14$ & $44.85 \pm 2.81$ & $88.61 \pm 10.47$ & $15.27 \pm 1.00$ \\
\hline $\begin{array}{c}\text { Moderately } \\
\text { Amnesic }\end{array}$ & $11.28 \pm 4.55$ & $32.54 \pm 5.40$ & $57.77 \pm 13.10$ & $10.46 \pm 3.05$ \\
\hline Severe Amnesic & $5.09 \pm 4.55$ & $12.91 \pm 5.54$ & $18.04 \pm 10.93$ & $4 \pm 4.34$ \\
\hline
\end{tabular}

Table 2 - Average score (and standard deviation) for each cluster defined group on the four FCSRT measures considered in the cluster analyses.

\begin{tabular}{|l|c|c|c|}
\hline & Pure-AD & Mixed-AD & Non-AD \\
\hline Non-amnesic & $20.0 \% *(3)$ & $38.5 \%(10)$ & $56.0 \%(28)$ \\
\hline Moderately amnesic & $66.7 \% *(10)$ & $57.7 \% *(15)$ & $28 \%(14)$ \\
\hline Severely amnesic & $13.3 \%(2)$ & $3.8 \%(1)$ & $16 \%(8)$ \\
\hline & & & $44 \%(22)$ \\
\hline Amnesic (moderately & $80 \% *(12)$ & $61.5 \%(16)$ & \\
\hline
\end{tabular}

Table 3 - Proportion (number) of non-amnesic, moderately amnesic, severely amnesic and amnesic (i.e. moderately+severely) patients within the different pathological groups as identified by the clustering analysis. * Significant difference with Non-AD. 


\section{Figures title \& legends}

Figure 1 - (A) Dendrogram using Ward's linkage based on squared Euclidean distance showing the cluster architecture of the 91 patients divided into three distinct clusters composed from non-amnesic (45.1\%), moderately amnesic (42.9\%) and severely amnesic (12.1\%) patients. (B) Relative distribution of neuropsychological scores employed as interclusters predictors and classified according to their level of importance. Frequency is on the vertical axis and FCSRT score on the horizontal (with lowest score on the left). FCSRT=Free \& Cued Selective Remining Test; TR=Total Recall; Cueing=Sensitivity to cues; DTR=Delayed Total Recall; FR=Free Recall.

Figure 2 - Distribution of pure-AD, mixed-AD and non-AD neuropathological diagnoses in the three clusters of memory performance according to the FCSRT.

Figures should be printed in black and white. 